\title{
The Economics of Repeated Extortion
}

by

Jay P. Choi, Columbia University

September 1998

Discussion Paper Series No. 9899-03

$$
\begin{aligned}
& d p 989-03 \\
& \text { proges: } 30
\end{aligned}
$$




\title{
The Economics of Repeated Extortion*
}

\author{
by \\ Jay Pil Choi \\ Columbia University \\ Marcel Thum \\ University of Munich
}

\section{September 1998}

\begin{abstract}
This paper provides a simple model of repeated extortion. In particular, we ask whether corrupt government officials' ex post opportunism to demand more once entrepreneurs have made sunk investments entails further distortion in resource allocations. We show that the inability of government officials to commit to future demands does not distort entry decisions any further if technology is not a choice variable for the entrepreneurs. The government official can properly discount the initial demand in order to induce the appropriate amount of entry. If, however, the choice of technology is left to the entrepreneurs, the dynamic path of demand schedules will induce entrepreneurs to pursue a "fly-by-night" strategy by adopting a technology with an inefficiently low sunk cost component. In this case, we show that the unique equilibrium is characterized by a mixed strategy of the government official in future demand. Our model thus explains why arbitrariness is such an inseparable feature of corruption. We also investigate implications of the stability of the corrupt regime for dynamic extortion and discuss how our framework can be applied to other investment contexts involving the risk of expropriation.
\end{abstract}

JEL Classification: D9, $\mathrm{H} 2, \mathrm{~K} 4, \mathrm{~L} 1$.

Keywords: comuption, repeated extortion, ex post opportunism, dynamic consistency, dynamic cream skimming.

Correspondence address:

Jay Pil Choi

Marcel Thum

Department of Economics

Center for Economic Studies

Columbia University

New York, NY 10027

U.S.A.

University of Munich

Schackstrasse 4

80539 Munich, Germany

e-mail: jpc8@columbia.edu

e-mail: mthum@ces.vwl.uni-muenchen.de

\footnotetext{
- This research was begun while the first author was visiting the Center for Economic Studies, University of Munich. We are grateful to Drew Fudenberg, Eric Maskin, John McLaren and Klaus Schmidt for helpful discussions.
} 


\section{Introduction}

Corruption is deemed by many economists to be detrimental to investment incentives leading to lower economic growth. Government officials, for instance, charge entrepreneurs for permits and licenses that they require to operate a business. These licenses, sold to maximize the officials' private gains, constitute an additional burden on new businesses [Shleifer and Vishny 1993]. Despite some arguments for beneficial effects of corruption [Leff 1964; Huntington 1968], recent empirical findings support the view that corruption is harmful to investment activities. Mauro [1995] shows that corruption lowers private investment, thereby reducing economic growth. In a study of the effect of corruption on foreign direct investment (FDI), Wei [1997a] finds that a rise in the corruption level in a host country reduces the inflow of FDI. In particular, an increase in the corruption level from that of Singapore to that of Mexico is shown to be equivalent to an increase in the tax rate of more than 20 percentage points. ${ }^{1}$

This paper is concerned with the dynamics of corruption. More specifically, we ask whether the government officials' ex post opportunism to demand more once entrepreneurs have made sunk investments entails further distortion in resource allocations. To answer this question, we develop a simple model of repeated extortion. As in Shleifer and Vishny [1993], we consider the sale of government property by government officials as the prototype of extortion activities. We show that the inability of government officials to commit to future demands does not distort entry decisions any further if the choice of technology is not a decision variable for the entrepreneurs. The government official can properly discount the initial demand in order to induce the appropriate amount of entry. If, however, the choice of technology is left to the entrepreneurs, the dynamic path of demand schedules will induce entrepreneurs to adopt an inefficient "fly-by-night" strategy. They will choose a technology

\footnotetext{
${ }^{1}$ Corruption is not an activity that is confined to any particular corner of the world. Even though there are large differences in the level of corruption between countries, some type of corruption can be found in almost every country. Even for the US which is usually ranked highly in terms of efficient, non-corrupt bureaucracies, Fesler and Kettl [1991, pp. 332f.] report that "in an FBI 'sting' operation, 105 out of 106 offers of bribes to suspected municipal officials in the State of New York were accepted; the $106^{\text {th }}$ was rejected as too small". At the other end of the corruption scale are countries like Uganda and Zaire. Under Idi Amin's regime in Uganda, for instance, government became little more than a system of organized crime used to extract rents from the public [World Development Report 1997, p. 106]. See Gould [1980] for a detailed analysis of corruption in Zaire.
} 
with inefficiently low sunk cost component, which allows them to react more flexibly to future demands from corrupt officials. We characterize the equilibrium behavior of the government officials and the entrepreneurs' technology choices. In particular, we show that there is no pure strategy equilibrium. Once entry decisions are made by entrepreneurs, the government officials' optimal strategy is to demand varying amounts of money. This provides a new interpretation of the arbitrariness that entrepreneurs often face in a corrupt environment; uncertainty is simply an equilibrium property of repeated extortion. ${ }^{2}$

The repeated demands in extortion are well-documented (see, for instance, John T. Noonan's [1984] comprehensive study on bribes). How extortion can almost become an art is illustrated by the case of cardinal Tommaso di Capua who became head of the Pope's Chancery under Innocent III in 1215. His letters written between 1215 and 1239 were even published a few years later in Summa Dictaminis - a handbook for correspondence in connection with 'presents'. Some gifts were sent back: "We have just become friends, don't rush it." Other letters give an eloquent but clear signal that additional payments are expected: "Be prepared to come back later (...) with fatter recompense (retributio). Therefore let your ready hand not grow lukewarm in the future nor put obstacle to later payments so that with repeated benefits you make your friends more devoted" [Noonan (1984, p. 201)]. A more contemporary example that nicely illustrates our point is the investment history of Gulf Oil Corporation in South Korea. In 1966, when Gulf had invested \$200 million in South Korea, the incumbent party asked for $\$ 1$ million contribution to finance its election campaign. As John T. Noonan $[1984,638]$ notes, "[t]he request was accompanied by pressure which left little to the imagination." Unfortunately for Gulf, elections are held repeatedly. So four years later, S.K. Kim, a leader of the incumbent party, asked again for a 'campaign contribution'. This time, the demand was $\$ 10$ million.

\footnotetext{
2 Scott [1972, p. 83] reports on corruption in Indonesia: "(...) in Indonesia the corruption 'market' was so disorganized that 'prices' were highly unstable and 'delivery' by sellers was highly uncertain." According to Robert Klitgaard's (1990, pp. 94f) description of corruption in Equatorial Guinea, "[t]here are no electricity meters so one might be asked to pay a million and a half cefas a month even though one had the generator going for twenty days." On the effects of comuption-induced uncertainty, Wei's [1997b] empirical study concludes that it is not only comuption itself but also the uncertainty created by corrupt officials that deters FDI.
} 
This paper builds on the works by Shleifer and Vishny [1993] and Bliss and Di Tella [1997]. Shleifer and Vishny's main concern is to investigate how the harmful effects of corruption depend on "the industrial organization of corruption." They argue that when corruption activities are decentralized, the harmful effects of corruption are accentuated. As different agencies set their bribery demands independently in order to maximize their own revenue, they do not take the negative externalities on other agencies' revenues into account. As in Cournot (1927), corruption among independently bribe-setting officials results in a lower level of entry and thus a lower aggregate level of revenue than the joint optimum. Bliss and Di Tella [1997] investigate the relationship between market competition and corruption. They recognize that the extent of competition is not an exogenous parameter since corruption itself can affect the number of firms in a free-entry equilibrium through the endogenously determined level of graft. In a model where the level of corruption and the extent of entry are co-determined by what they call "deep competition" parameters, they show that there is no simple relationship between competition and corruption, thus questioning the validity of a commonly held belief that competitive pressures in the market can mitigate corruption. In this paper, we are concerned with dynamic aspects of corruption. As in Bliss and Di Tella [1997], we abstract from the issue of coordination among corrupt officials and only consider a monopoly corruption scheme; there is only one official who can issue the license which is required to run a business and this official demands illegal side payments for his services. ${ }^{4}$ However, we extend the analysis to a dynamic situation where the official who has collected the bribe previously comes back to demand more. We analyze whether there are additional harmful effects on resource allocation due to the possibility of repeated extortion.

The formal structure of the problem is similar to the licensing model by Farrell and Gallini [1987] where consumers incur setup costs to use a new product. This creates a

\footnotetext{
${ }^{3}$ The seminal paper on the economics of corruption is Rose-Ackerman [1975]. For a recent survey of the literature, the reader is referred to Ades and Di Tella [1997].

${ }^{4}$ It is not always a subordinate government employee who exacts money from businesses in an ex post opportunistic manner. In $17^{\text {th }}$ century England, it was the Crown itself that expropriated wealth from citizens -against the will of the Parliament. One method used by the Crown was to demand 'loans' which were neither voluntarily given nor likely to be repaid [North and Weingast 1989]. In $19^{\text {th }}$ century US, local ruling party organisations forced utilities or other corporations to pay large bribes by threatening the firm to enact a legislation that would be harmful to the firm's investment [Miller 1989].
} 
dynamic consistency problem for the monopolist once consumers have incurred these costs. The main result is that second-sourcing through licensing can serve as a price commitment for the future when long-term contracts with consumers are infeasible due to the nonverifiability of quality. In our extortion model, however, there is no such mechanism to commit to a future demand since a corrupt official with the power to extort usually does not possess a credible mechanism to promise 'competition among corrupt officials' in the future. In the context of corruption, it is also natural to assume that the long-term contracts are not enforceable in that they involve illegal activities.

The remainder of the paper is organized in the following way. In Section II, we set up the basic model of dynamic extortion with only one type of technology. We show that the inability to commit to future demand does not entail further efficiency losses from the commitment solution because the official can give a discount in the first period for his future opportunistic behavior. In Section III, we enrich the model with the endogenous choice of technologies by potential entrants. In Section IV, we analyze how the stability of a corrupt regime affects economic performance. The dynamic problem analyzed in the paper can also be applied to various other situations where agents have the power to extort such as in organized crime and the expropriation of multinational corporations by host governments. We conclude with a brief discussion of these extensions.

\section{The Basic Model of Repeated Extortion}

We develop a two-period model of repeated extortion. Consider a government official who has the power to issue licenses that allow entrepreneurs to open a shop. ${ }^{5}$ The official sets the price of the license to maximize revenues from licensing. In addition to the licensee fee, entrepreneurs need to incur costs of $K$ to enter the business, which are assumed to be sunk.

Entrepreneurs are heterogeneous in their ability to generate (net) income in each period, denoted by $v$. Let us normalise the total population of entrepreneurs to unity. The

\footnotetext{
${ }^{5}$ As pointed out by Stigler (1971), "[t]he state has one basic resource which in pure principle is not shared with even the mightiest of its citizens: the power to coerce." The state's monopoly on coercion can lead to the abuse of power when public officials have wide discretion and little accountability due to the lack of formal checks and balances [World Development Report 1997].
} 
distribution of abilities is given by the inverse cumulative distribution function $F(v)$ with continuous density $F^{\prime} \leq 0$, that is, $F(v)$ denotes the proportion of entrepreneurs who can generate income more than $\mathrm{v}$ in each period. The type of entrepreneurs is private information to entrepreneurs. The government official knows only the distribution of types. Once the entrepreneurs have made their sunk investment, the official may require that for the continuation of the business the license be renewed later at a fee.

\section{The Static Problem}

We first analyse a static problem as a benchmark. This preliminary analysis also helps us develop notation. Consider the official's one-period static problem when the entrepreneur has operating cost of $c$. All players are assumed to be risk neutral. If the official demands $m$ for the license, the marginal type who is indifferent between entry and exit is given by $v=m+c$. Thus, the official solves:

$$
\max _{m} m \cdot F(c+m)
$$

The first order condition for the optimal $m$ is given by:

$$
F(c+m)+m \cdot F^{\prime}(c+m)=0
$$

We make the standard assumption that the distribution of types satisfies the monotone hazard rate condition, that is, $F^{\prime} / F$ is increasing:

$$
F^{\prime \prime} \cdot F-\left(F^{\prime}\right)^{2}>0
$$

This assumption ensures that the official's objective function is quasi-concave and the second order condition for the maximization problem is satisfied:

$$
2 \cdot F^{\prime}(c+m)+m \cdot F^{\prime \prime}(c+m)<0 .^{6}
$$

Let $m^{*}(c)$ be implicitly defined by (2) and be the solution to the above problem, i.e.,

$$
m^{*}(c)=\operatorname{argmax} m \cdot F(c+m)
$$

\footnotetext{
6 Using the first order condition, we can rewrite the second order condition as $2 \cdot F^{\prime}(c+m)-F^{\prime \prime}(c+m) \cdot F(c+m) / F^{\prime}(c+m)<0$. The second order condition holds if the distribution $F$ satisfies the monotone hazard rate condition. This condition is a standard assumption in the incentive literature and is satisfied by most widely used distributions; see Fudenberg and Tirole [1991, p. 267].
} 
and let $R(c)=m^{*}(c) \cdot F\left(c+m^{*}(c)\right)$ be the indirect revenue function for the official. Then, the marginal entrepreneur is given by $\nu^{*}(c)=c+m^{*}(c)$.

To obtain some comparative static results, we totally differentiate the first order condition (2):

$$
\frac{\partial m^{*}(c)}{\partial c}=-\frac{F^{\prime}+m \cdot F^{\prime \prime}}{[\text { s.o.c }]}
$$

where [s.o.c] denotes the second order condition (4) and is negative. By using the first order condition and condition (3), we can verify that the numerator is negative $\left(F^{\prime}+m \cdot F^{\prime \prime}<0\right)$. Thus,

(7) $\quad \partial m^{*}(c) / \partial c<0$.

As the operating cost of entrepreneurs increases, the optimal monetary demand by the official decreases. However, the overall effect of the increased operating cost on the extent of entry is negative:

$$
\frac{\partial^{*}(c)}{\partial c}=\frac{\partial\left[c+m^{*}(c)\right]}{\partial c}=\frac{F^{\prime}}{[\text { s.o.c }]}>0
$$

By using the envelope theorem, we can also verify that

$$
\frac{\partial R(c)}{\partial c}=m^{*}(c) \cdot F^{\prime}<0
$$

The official's revenue decreases with the increase of the entrepreneurs' operating cost.

\section{The Dynamic Problem with Commitment}

We now consider a dynamic (two-period) problem where the official can come back to demand more in the second period. The timing is as follows. At the beginning of the first period, the official demands $m_{1}$ as a licensee fee for opening a business. Potential entrepreneurs know their own type $(v)$ and decide whether to enter or not. If they enter, they have to make specific investment of $K$ which is not recoverable upon exit. Let us assume that there is no further operating cost once the sunk investment is made. ${ }^{7}$ In the second period, the official can demand more money $\left(m_{2}\right)$ as a license renewal fee given the number of firms that

\footnotetext{
${ }^{7}$ This assumption is made without any loss of generality since we can interpret $v$ as the income generated net of any operating cost.
} 
entered in the first period. The firms who entered in the first period decide whether to stay in the business by paying $m_{2}$ or exit from the market (see Figure 1). Those firms that did not enter in the first period can potentially enter the market in the second period by paying $m_{2}$ in addition to the sunk cost of $K$. As shown in the Appendix, however, there will be no new entry in the second period in equilibrium.

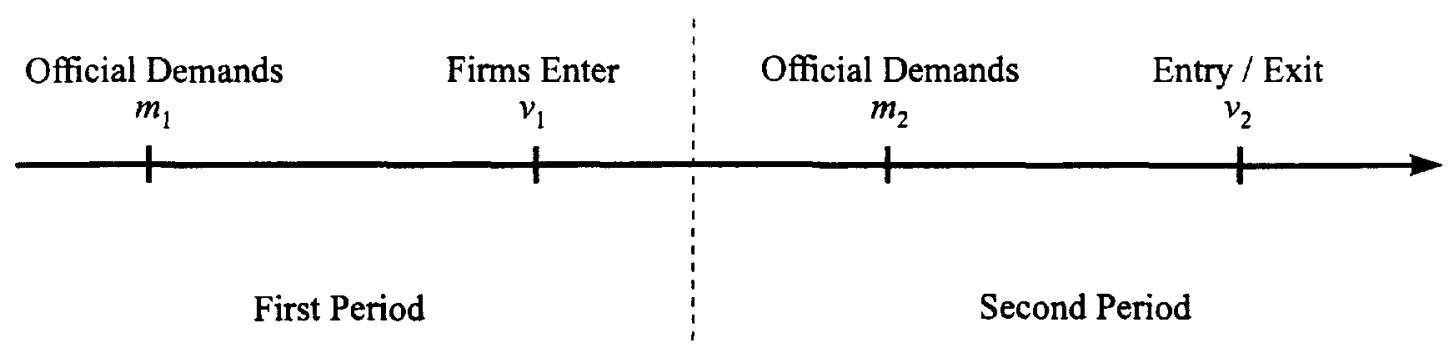

Figure 1. The Timing of Repeated Extortion Game

The official cannot price discriminate against the existing firms and give discounts to new entrants in the second period. This reflects our assumption about the information structure the government official has in the second period about individual entrepreneurs. We assume that the entrepreneurs are anonymous in that the existing firms can disguise as new entrants if any discounts are offered to new entrants. ${ }^{8}$ This implies that there are no incentives for the entrepreneurs to delay their entry to disguise as low types in order to elicit the discount later, as in the ratchet model (Freixas, Guesnerie, and Tirole, 1985; Laffont and Tirole, 1988).

The official cannot commit to $m_{2}$ before entry occurs in the first period. Thus, the official has the temptation to exploit those who incurred sunk costs in the first period. In this setting, we ask whether the official's ex post opportunism distorts the resource allocation any further. To answer this question, however, we first consider the counterfactual case where the official can commit to his future demand in the first period before the entry decisions are made

Let $m_{1}$ and $m_{2}$ be the monetary demands by the official in period 1 and period 2 , respectively. In Appendix A1, we establish that the optimum is to have the same number of firms in both periods. ${ }^{9}$

\footnotetext{
${ }^{8}$ It may be technically feasible to give discounts to existing firms by demanding them to submit the original license. However, there is no incentive to do that for the official in the second period.

${ }^{9}$ A similar proof is given in Farrell and Gallini (1987) in the context of technology adoption.
} 
Given that the number of firms staying in the market is constant across periods in the optimum, the marginal type who is indifferent between entry and exit is defined by $v \cdot(1+\delta)=K+m_{1}+\delta \cdot m_{2}$, where $\delta<1$ is the discount factor. For the marginal investor $\left[v=\left(K+m_{1}+\delta \cdot m_{2}\right) /(1+\delta)\right]$, the present value of profits has to be equal to the start-up costs plus the present value of bribes. Thus, in the commitment solution, the corrupt official solves the following problem:

$$
\underset{m_{1}, m_{2}}{\operatorname{Max}}\left(m_{1}+\delta \cdot m_{2}\right) \cdot F\left[\frac{K}{1+\delta}+\frac{m_{1}+\delta \cdot m_{2}}{1+\delta}\right]
$$

Let $\bar{m}=\left(m_{1}+\delta \cdot m_{2}\right) /(1+\delta)$ be the average discounted monetary demand by the official. Then, the first order condition can be written as:

$$
F\left(\frac{K}{1+\delta}+\bar{m}\right)+\bar{m} \cdot F^{\prime}\left(\frac{K}{1+\delta}+\bar{m}\right)=0
$$

The optimal commitment solution is $\bar{m}^{c}=m *(K / 1+\delta)=\left(m_{1}{ }^{c}+\delta \cdot m_{2}{ }^{c}\right) /(1+\delta)$. In other words, any combination of $\left(m_{1}{ }^{C}, m_{2}{ }^{\top}\right)$ that has the same discounted average of $\bar{m}^{c}=m *(K / 1+\delta)$ can be the optimal solution. For instance, constant demands of $m_{1}=m_{2}=m *(K / 1+\delta)$ are optimal. The marginal entrant is $v^{c}=K / 1+\delta+m *(K / 1+\delta)$.

Proposition 1. Any combination of $m_{1}{ }^{c}(>0)$ and $m_{2}{ }^{c}$ that has the same discounted average value of $\left(m_{1}{ }^{c}+\delta \cdot m_{2}{ }^{c}\right) /(1+\delta)=\bar{m}^{c}=m^{*}(K / 1+\delta)$ is optimal for the corrupt official. The marginal type of entrepreneur who is indifferent between entering and staying out is given by $v^{c}=K / 1+\delta^{+}+m *(K / 1+\delta)$. Thus, the solution is equivalent to the repetition of the static revenue maximization problem when the entrepreneurs' per period cost is given by $K / 1+\delta$.

\section{The Dynamic Problem without Commitment}

Now let us analyze the case where the official cannot commit to the future level of demand before the entry decision is made. In this case too, we can demonstrate that the optimal strategy is to induce a constant number of firms to stay in business for both periods (see Appendix A1). Let us denote $v^{N C}$ as the marginal type when no commitment is possible. 
Then, the official will demand $m_{2}{ }^{N C}=v^{N C}$ in the second period. Given that the whole surplus is extracted in the second period for the marginal type, the first period demand should be sufficiently low to induce the marginal type to invest in the sunk cost which implies that $m_{1}{ }^{N C}=v^{N C}-K$. Since the time-consistent demand schedule $\left(m_{1}^{N C}, m_{2}^{N C}\right)$ is uniquely determined by $v^{N C}$, we will find it more convenient to treat $v^{N C}$ as the control variable. Thus, the maximization problem for the official can be written as:

$$
\underset{v^{N C}}{\operatorname{Max}}\left(m_{1}+\delta \cdot m_{2}\right) \cdot F\left(v^{N C}\right)=\left[\left(v^{N C}-K\right)+\delta \cdot v^{N C}\right] \cdot F\left(v^{N C}\right)
$$

The first order condition for $v^{N C}$ is given by:

$$
F\left(v^{N C}\right)+\left[v^{N C}-K / 1+\delta\right] \cdot F^{\prime}\left(v^{N C}\right)=0
$$

Thus,

$$
v^{N C}-\frac{K}{1+\delta}=m *\left(\frac{K}{1+\delta}\right)
$$

determines the optimal marginal type [see (5) for the definition of the $\mathrm{m}^{*}$-function]. Using the information on the marginal type we obtain a solution for the official's optimal bribery demands when no commitment is possible:

$$
\begin{aligned}
& m_{1}^{N C}=v^{N C}-K=m *\left(\frac{K}{1+\delta}\right)-\frac{\delta \cdot K}{1+\delta} \\
& m_{2}^{N C}=v^{N C}=m *\left(\frac{K}{1+\delta}\right)+\frac{K}{1+\delta}
\end{aligned}
$$

That is, the government official discounts the initial demand by the amount of sunk cost $\left(m_{2}^{N C}-m_{1}^{N C}=K\right)$ to compensate for his ex post opportunistic behavior.

The optimal time-consistent demand schedule above was derived assuming that the first period demand can be negative (i.e., the initial subsidy for entry). This assumption corresponds to the case where the sunk investment is mainly in physical capital so that the official can verify whether the investment has been undertaken by the entrepreneurs who received the subsidy. Alternatively, the official is able to provide the sunk investment himself. Otherwise, the entrepreneurs will just take the money and disappear without any investment. In such a case, we can easily verify that there are no differences between the 
cases of commitment and no commitment in terms of the number of entrants and the government official's revenue. Since the government official can induce the optimal amount of entry by appropriately discounting his initial demand, there is no additional cost associated with the dynamic consistency requirement.

However, there may be cases where we should impose the non-negativity constraint on the initial demand $\left(m_{1}^{N C} \geq 0\right)$. For instance, the sunk investment may represent mainly human capital components which cannot be observed. Then, the commitment solution can be replicated only when the nonnegative constraint is not binding $\left(m_{1}^{N C} \geq 0\right)$, in which case the optimal solution is once again given by (15). More specifically, note that $m^{*}(K / 1+\delta)$ is decreasing in $K$ (Eq. (7)), which makes $m_{1}^{N C}=m *(K / 1+\delta)-\delta \cdot K / 1+\delta$ a monotonically decreasing function of $K$; there exists a unique critical value $\bar{K}$ such that $m_{1}^{N C} \geq 0$ if and only if $K \leq \bar{K}$. Therefore, if the cost of sunk investment is substantial $(K>\bar{K})$, the non-negative constraint is binding and the optimal solution is given by:

$$
m_{1}^{N C}=0, \quad m_{2}^{N C}=v^{N C}=K
$$

Note that in this case $(K>\bar{K})$, the no commitment solution entails an efficiency loss compared to the commitment solution in that there is too little entry $\left(v^{N C}=K>v^{C}=K / 1+\delta+m *(K / 1+\delta)\right.$.

Proposition 2. Let $\bar{K}$ be the unique value that satisfies $m *(K / 1+\delta)=\delta \cdot K / 1+\delta$. If $K \leq \bar{K}$, the optimal time-consistent extortion schedule is $m_{1}^{N C}=m^{*}(K / 1+\delta)-\delta \cdot K / 1+\delta$ and $m_{2}^{N C}=m *(K / 1+\delta)+K / 1+\delta$. There is no further efficiency loss due to the government official's inability to commit to future demand in that $v^{N C}=v^{C}=K / 1+\delta+m *(K / 1+\delta)$. If $K$ $>\bar{K}$, the optimal schedule is $m_{1}^{N C}=0, m_{2}^{N C}=v^{N C}=K$. In this case, the optimal solution induces too little entry. In both cases, the official offers a first-period discount for the cost of sunk investment to satisfy the dynamic consistency requirement.

We can conclude that unless the cost of sunk investment is sufficiently large, there is no further inefficiency loss due to repeated extortion. However, we note that the demand schedule is increasing over time due to the initial discount $\left(m_{2}^{N C}-m_{1}^{N C}=K\right)$. In the next 
section, we argue that the entrepreneurs' incentive to take advantage of the initial discount may lead to inefficient entry behavior if the choice of technology is endogenous. In the remainder of this paper, we will simply assume that $K \leq \bar{K}$ to abstract from inefficiency considerations due to the binding non-negative constraint on initial demand. ${ }^{10}$

\section{Dynamic Extortion and the Choice of Technology}

Now we assume that entrepreneurs have available another type of technology with which to enter the market. More specifically, this alternative technology entails less sunk cost and higher per-period operating costs. For simplicity, this technology is assumed to involve no sunk costs and operating costs of $k$ per period, where $(1+\delta) \cdot k>K>k$. Thus, the alternative technology is less efficient if production takes place in both periods. However, it protects the entrepreneur from the official's ex post opportunistic behavior because it does not involve any sunk capital. We assume that the official cannot observe which type of technology has been chosen in the first period and thus cannot price discriminate based on the type of technology chosen. For instance, the sunk cost can be considered as an investment in specific human capital relevant for the business.

With the availability of this short-term investment strategy, the optimal dynamic demand schedule cannot be sustained. To see this, consider the marginal type who was indifferent between entering and staying out in the no commitment case, $v^{N C}=K / 1+\delta+m *(K / 1+\delta)$. This marginal type's surplus was completely extracted with the choice of the $K$-technology. The marginal type, however, can do better when the $k$ technology becomes available. Facing the demand schedule, $m_{1}^{N C}=m *(K / 1+\delta)-\delta \cdot K / 1+\delta$ and $m_{2}^{N C}=m *(K / 1+\delta)+K / 1+\delta$, he can enter by choosing the $k$-technology in the first period when the discount is offered by the official and exit in the second period when the amount of extortion is increased - a strategy that may be called dynamic cream skimming. ${ }^{11}$ Choosing this altemative technology with less sunk costs yields the payoff

\footnotetext{
${ }^{10}$ In contrast, Farrell and Gallini's (1986) analysis of licensing focuses on the case where the non-negativity constraint is binding.

"Cream skimming in the regulation literature refers to the inefficient firm's selective entry into the most profitable markets when the regulated incumbent firm practices cross subsidization between markets (Viscusi,
} 


$$
v^{N C}-k-m_{1}^{N C}=K-k>0 .
$$

In fact, with the demand schedule of $\left(m_{1}^{N C}, m_{2}^{N C}\right)$, any entrant below type $v=v^{N C}+(K-k) / \delta$ will choose the $k$-technology and exit from the market in the second period when $m_{2}^{N C}$ is demanded. Thus, the optimal schedule identified in the previous section is no longer optimal with the availability of a short-term investment strategy.

What will the equilibrium look like when the entrepreneurs can shield themselves from the official's ex post opportunism by choosing the short-term investment strategy? We first argue that there is no pure strategy equilibrium in the presence of the $k$-technology.

Proposition 3. There is no pure strategy equilibrium when the choice of technology is endogenous.

Proof. See Appendix A2.

The intuition for the non-existence of a pure strategy equilibrium can be explained as follows. In the second period, the official's optimal choice is either to take advantage of the entrepreneurs who entered with the $K$-technology or to allow additional entrants with the ktechnology. If the official chooses the first option for sure, the marginal type whose entire surplus is extracted in the second period with the $K$-technology has an incentive to switch to the $k$-technology. Thus, the first option cannot be sustained as an equilibrium. If the second option is chosen for sure, the marginal entrant with the k-technology can be better off by entering with the $K$-technology in the first period, once again upsetting the putative pure strategy equilibrium. Thus, there is no pure strategy equilibrium.

To derive the mixed strategy equilibrium, we prove in Appendix A3 that the choice of technology is characterized by the following cut-off rule.

Lemma 1. There is a critical value $\hat{v}$ such that all types above it choose the $K$-technology whereas all entrants below it choose the $k$-technology in equilibrium.

Vernon, and Harrington, 1995). In our model, the first period discount in the optimal demand schedule can be interpreted as intertemporal subsidization. 
Given Lemma 1, suppose that all the types above type $\hat{v}$ have entered with the $K$ technology in the first period. In the second period, the relevant state variable for the official is the cut-off value $\hat{v}$ of the entrepreneurs' types who have chosen the $K$-technology. There is no distinction between those who have entered with the k-technology and those who stayed out in the first period because both have to incur the same cost of $k$ to operate in the second period.

Lemma 2. For the official to adopt a mixed strategy, the critical type $\hat{v}$ must be larger than $v^{*}(0)=m^{*}(0)$.

Proof. Suppose not, i.e., $\hat{v} \leq v^{*}(0)$. Then, the optimal strategy for the official in the second period is to demand $m_{2}=v^{*}(0)=m^{*}(0)$ with probability 1 . Thus, we have a contradiction.

Given that $\hat{v}>v^{*}(0)$, the optimal demand in the second period is either to charge $\hat{v}$ which prevents any entry with the $k$-technology or to charge $m^{*}(k)$ which allows entry with the marginal type $v^{*}(k)=k+m^{*}(k)$. The corrupt official receives a revenue of $\hat{v} \cdot F(\hat{v})$ in the former case and of $R(k)=m^{*}(k) \cdot F\left(k+m^{*}(k)\right)$ in the latter case. For the official to mix between these two demands, he has to be indifferent between the two strategies:

$$
\hat{v} \cdot F(\hat{v})=m^{*}(k) \cdot F\left(k+m^{*}(k)\right)
$$

Condition (16) pins down the critical type $\hat{v}$ who should be indifferent between entering with the $K$-technology and the $k$-technology; $\hat{v}$ is the larger root to equation (16). See Figure 2.

Lemma 3. $\hat{v}>v^{*}(k)=k+m^{*}(k)\left|>v^{c}=K / 1+\delta+m^{*}(K / 1+\delta)\right|$.

Proof. Recall that $\hat{v}$ is the larger root to equation (16):

$$
\hat{v} \cdot F(\hat{v})=m^{*}(k) \cdot F\left(k+m^{*}(k)\right)<\left[k+m^{*}(k)\right] F\left(k+m^{*}(k)\right)
$$

Since $\phi(v)=v F(v)$ is a quasi-concave function of $v$ and at $\hat{v}, \phi^{\prime}(v)<0$, we have

$$
\hat{v}>v^{*}(k)=k+m^{*}(k) \text {. }
$$

Lemma 3 is illustrated in Figure 2. 


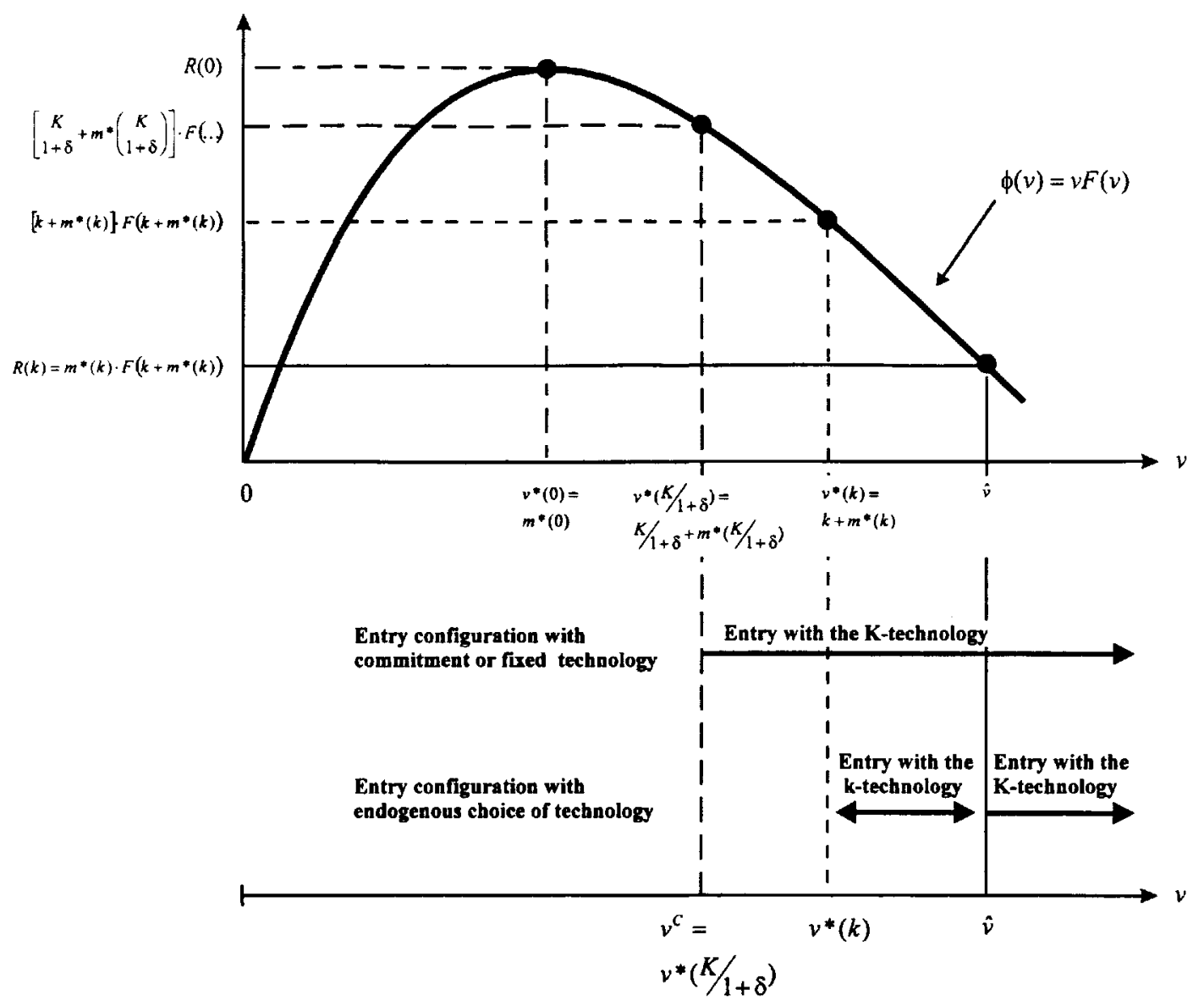

Figure 2. Equilibrium with Endogenous Choice of Technologies

A corollary of Lemma 3 is that there are two types of inefficiencies associated with the availability of the short-term investment strategy $k$. First, there is too little entry compared to the previous case $\left(v^{*}(k)>v^{c}\right)$. Second, some of those who enter do so with an inefficient technology $k\left(v \in\left[v^{*}(k), \hat{v}\right]\right)$.

The mixing probability for the official is determined by the indifference condition for the $\hat{v}$-type. Let $\alpha$ be the probability that the official chooses to demand $\hat{v}$. The condition for the critical type to be indifferent between the two technologies is:

$$
\hat{v}-K-m_{1}+\delta \cdot(1-\alpha) \cdot\left[\hat{v}-m^{*}(k)\right]=\hat{v}-k-m_{1}+\delta \cdot(1-\alpha) \cdot\left[\hat{v}--k-m^{*}(k)\right]
$$

Therefore, the official charges $\hat{v}$ with probability $\alpha=\left[(1+\delta) \cdot k-K \bigvee[\delta k]\right.$ and $m^{*}(k)$ with probability $(1-\alpha)=(K-k) /[\delta k]$.

Proposition 4. When the choice of technology is endogenous, the corrupt official employs a mixed strategy with respect to his future bribery demand in equilibrium. 
Proposition 4 explains why corruption is so often embedded with arbitrariness and creates uncertainty. It also provides a new interpretation of Wei's (1997b) recent empirical study on corruption. He examines the effect of corruption-induced uncertainty on foreign direct investment and shows that the second moment (variability) effect is negative, statistically significant and quantitatively large. For instance, an increase in the uncertainty level from that of Singapore to that of Mexico, at the average level of corruption in his sample, is equivalent to raising the tax rate by 32 percentage points. Wei's empirical result is based on a model where the level of foreign investment is adversely affected by the increase in the variability of the bribe rate due to the foreign investors' risk aversion. Our model, however, suggests that there is no causal relationship between uncertainty and inefficient investment behavior. In our model, the entrepreneurs are risk-neutral and the inefficiency stems from the entrepreneurs' incentive to practice dynamic cream skimming. Uncertainty per se is not a deterrent to investment. Uncertainty is rather a part of equilibrium and is endogenously determined together with the level of investment and the choice of technology.

In Wei's model, uncertainty is treated as an exogenous variable. Thus, one obvious policy implication of his model would be to make the bribery schedule as transparent as possible to promote foreign direct investment. In contrast, our model not only explains the genesis of corruption-induced uncertainty, but also demonstrates that arbitrariness is an inseparable feature of corruption, which cannot be tackled in isolation.

\section{The Stability of a Corrupt Regime}

We now consider how the stability of a corrupt regime affects economic performance. Let us parametrize the stability of the regime by $\beta$ which is the probability that the official will remain in power in the second period. We consider two scenarios. In the first scenario, if the corrupt official loses power in the second period, he is replaced by another corrupt official. In this case, the change of power is irrelevant for the entrepreneurs while it matters a lot to the original corrupt official who loses power. In the second scenario, the change of power takes place through a genuine reform where corruption is eliminated in the second period. In this 
section, we abstract from the issue of endogenous technology choice; only the $K$-technology is available to entrepreneurs. We also ignore discounting by setting $\delta=1$.

\section{IV.1. Succession of Corrupt Regimes}

Consider the case where the official in the first period remains in power only with probability $\beta$ in the second period. Thus, $\beta$ plays the role of a discount factor for the official. If there is a change of power, the office is transferred to another corrupt official. As a result, second period demands will be independent of who is in power. Once again, it can be shown that the optimal strategy in the second period is to extract the whole surplus of the marginal type who entered in the first period without inducing any exit. Thus, the marginal type is given by $\hat{v}=m_{1}+K$.

The maximization problem for the official in the first period then is:

$$
\underset{m_{1}}{\operatorname{Max}} m_{1} \cdot F\left(m_{1}+K\right)+\beta \cdot\left(m_{1}+K\right) \cdot F\left(m_{1}+K\right)
$$

The first order condition is given by:

$$
F\left(m_{1}+K\right)+\left[m_{1}+\beta \cdot K /(1+\beta)\right] \cdot F^{\prime}\left(m_{1}+K\right)=0
$$

Totally differentiating Eq. (19) with respect to $m_{1}$ and $\beta$ yields:

$$
[\text { s.o.c }] d m_{1}+\frac{K}{(1+\beta)^{2}} \cdot F^{\prime}\left(m_{1}+K\right) d \beta=0,
$$

where [s.o.c] denotes the second order condition for (18) and is negative. Thus, we have $d m_{1} / d \beta<0$. As the corrupted regime becomes more stable, there will be more discounts in the first period demand, which induces more entry in the first period.

Proposition 5. When a transfer of power may take place between corrupt officials, the stability of the regime is conducive to economic performance. A policy that fights corruption but cannot ensure that corrupt officials are replaced by honest ones is detrimental to economic activity.

This result is complementary to Shleifer and Vishny (1993). They show in a static setting that interagency externalities aggravate the problem of corruption in comparison to the 
simple monopoly corruption scheme. Weak governments cannot prevent its numerous agencies from setting their own bribes independently, thus maximising the private profit of each agency. When an entrepreneur who wants to start a business needs services from several of these agencies, each agency will neglect the externality it creates on the bribery revenue of other agencies. A higher bribery demand of one agency reduces the willingness to pay for complementary services. Due to this externality, the amount of economic activity is lower in equilibrium than with a monopoly corruption scheme. In our model, a stable regime enables the official to internalize the intertemporal externality stemming from the existence of sunk cost. Thus, the official is more willing to invest (discount) in the first period demand when he is more confident that he would reap the benefits in the second period.

Our result also has implications for job transfers often observed in various organizations such as planned enterprises in the former Soviet Union, the U.S. foreign service and military. The practice can be puzzling since transferring individuals to new jobs sacrifices job-specific human capital (Ickes and Samuelson, 1987). One explanation is that job transfers prevent corruption by ensuring that employees do not occupy a job long enough to reap the benefits of corrupt activities. ${ }^{12}$ Our model, however, suggests that job transfers intended to mitigate corruption may have the exact opposite effect.

\section{IV.2. Reform Case}

Now consider the case where the corrupt regime may be replaced by an honest government through a genuine reform. In this case, the transfer of power matters not only to the initial corrupt official but also to entrepreneurs. If the corrupt official retains power in the second period, it is optimal to extract the whole surplus of the marginal type who entered in the first period without inducing any exit as in the previous case. However, in the case of genuine reform, entrepreneurs may have an incentive to delay their investment, hoping for the installation of a clean government. With international organisations such as the IMF and the World Bank putting more emphasis on the efficiency of government institutions in aid-

\footnotetext{
${ }^{12}$ Other explanations for job transfers include mitigating the ratchet effect, sorting employees into the jobs where they will be the most productive, and allowing potential future managers to gain familiarity with various aspects of an organization's operations. See Ickes and Samuelson (1987) for details.
} 
receiving countries, this case has particular relevance for the future. In August 1997, for instance, the IMF issued new guidelines making the reform of corrupt institutions a prerequisite for financial aid [IMF 1997]. These conditionalities can be viewed as a sign of national commitment to policy reforms for countries with weak domestic commitment mechanisms [World Development Report 1997].

Given a bribery demand of $m_{1}$, the marginal type who enters is defined by:

$$
\left(\nu-K-m_{1}\right)+(1-\beta) \cdot v=(1-\beta) \cdot(\nu-K)
$$

The left-hand side of Eq. (21) represents the expected payoff from entering in the first period and the right-hand side represents the option value of delaying the investment until the second period. The marginal type is given by $\hat{v}=m_{1}+\beta \cdot K$. The maximization problem for the official in the first period is:

$$
\operatorname{Max}_{m_{1}} m_{1} \cdot F\left(m_{1}+\beta \cdot K\right)+\beta \cdot\left(m_{1}+\beta \cdot K\right) \cdot F\left(m_{1}+\beta \cdot K\right)
$$

The first order condition is given by:

$$
F\left(m_{1}+\beta \cdot K\right)+\left[m_{1}+\left(\beta^{2} \cdot K\right) /(1+\beta)\right] \cdot F^{\prime}\left(m_{1}+\beta \cdot K\right)=0
$$

Thus, the optimal demand in the first period is

$$
m_{1}=m^{*}\left(\frac{\beta K}{1+\beta}\right)-\frac{\beta^{2} \cdot K}{1+\beta},
$$

which we can rewrite as

$$
m_{1}=m^{*}\left(\frac{\beta K}{1+\beta}\right)+\frac{\beta \cdot K}{1+\beta}-\beta \cdot K
$$

[see (5) for the definition of the $m^{*}$-function]. In general, the overall effect of the stability of the regime on the first period bribery demand depends on the relative magnitude of the two countervailing effects. As the probability of a new regime increases, the corrupt official has less incentive to internalize the intertemporal externality and thus increases the bribery demand in the first period. However, the entrepreneurs have less incentives to delay their investments since the risk of ex post expropriation is reduced with the increase in the probability of a new regime. Thus, the corrupt official can get away with less discount in the first period. 
It turns out that the first effect dominates the second and we have $d m_{1} / d \beta<0$ as in the previous case. To verify this, note that both $\frac{\beta K}{1+\beta}$ and $\frac{\beta^{2} \cdot K}{1+\beta}$ in Eq. (24) are increasing in $\beta$ and that $m^{*}($.$) is a decreasing function.$

The effect of stability on the aggregate investment level, however, is opposite to the previous case. The marginal type is given by:

$$
\hat{v}=m_{1}+\beta \cdot K=m *\left(\frac{\beta \cdot K}{1+\beta}\right)+\frac{\beta \cdot K}{1+\beta} .
$$

Since $\beta \cdot K / 1+\beta$ is increasing in $\beta$, the cut-off value $\hat{v}$ increases with $\beta$ [see Eq. (8)]. We conclude that the effect of stability of a corrupt regime on the extent of entry is harmful in this case. In other words, the possibility of future reform has a positive effect on current aggregate investment. Thus, it is important to distinguish the two cases of regime changes since the stability of a corrupt regime has different implications for investment activities depending on the nature of regime change.

\section{Concluding Remarks}

In this paper, we have analyzed the consequences of repeated extortion. It turned out that the repeated nature of extortion per se does not create further distortions in resource allocations. There are no fewer businesses in operation when corrupt officials can make repeated bribery demands than when there are once-and-for-all bribery payments. The reason is that a corrupt official can properly discount his initial demand in order to induce the appropriate amount of entry. The major inefficiency of repeated extortion emerges only when entrepreneurs have discretionary power over the choice of technology. In that case, entrepreneurs react to the dynamic path of bribery demands by distorting their choice of technology in the form of inefficiently low sunk investments. This type of investment behavior allows them to react more flexibly to future extortion. We have also shown how the stability of a corrupt regime affects extortion and investment activities. A corrupt official who fears to lose his power in the future becomes less willing to discount his future demands, thus driving more entrepreneurs out of business. 
We conclude with a discussion on how the dynamic problem analyzed in the paper can be applied to other situations that involve agents who have the power to extort. We also mention how the basic framework can be extended depending on the contexts.

\section{Organized Crime}

The most obvious example is organized crime. ${ }^{13}$ Gangs charge 'protection money' from businesses and this kind of extortion is typically done repeatedly. The dynamic nature of the extortion game has serious consequences for behavior on both sides -- the gang and the entrepreneurs. Entrepreneurs become more reluctant to put larger sums in sunk investments. They may choose technologies that are deemed inefficient in the absence of organized crime to be able to react more flexibly to extortive threats. In response to the incomplete information about the types of technologies chosen, the gang may randomly change the sum of 'protection money' which it demands from businesses.

One important aspect of extortion that is not considered in our model is how gangs actually try to overcome the information asymmetry in order to improve on their rewards of extortion. This can be achieved, for instance, by forcing businesses to purchase complementary inputs from gang owned firms. In the case of the Fulton Fish Market in Manhattan, fish dealers were forced to hire certain (Mafia owned) companies performing the loading function. This arrangement enabled the gang to observe how much fish was traded by each dealer. The sums extorted from each fish dealer could then be related to the volume of loaded or unloaded fish by charging excessive loading fees. ${ }^{14}$ In 1995 , when the City of New York installed a regulatory authority to manage the market in an effort to drive organized crime out of Fulton Fish Market, loading costs dropped by 70 percent [Giuliani 1997]. ${ }^{15}$

\section{Sale of Public Offices}

Sale of public offices was a prevalent phenomenon in many countries and over long periods in the history of states. Sale of offices, in particular the offices of tax collectors, had great

\footnotetext{
${ }^{13}$ For an economic analysis of extortion by organized crime, see Konrad and Skaperdas [1997, forthcoming].

${ }^{14}$ The economic rationale for this arrangement is similar to the price discrimination motives for tying where the practice serves as a metering device [Telser, 1979].

${ }^{15}$ It is estimated that the control over Fulton Fish Market brought $\$ 50$ million a year into the mob's treasury [Vulliamy 1998].
} 
advantages when the honesty of officials was hard to monitor or when the potential for tax revenues in distant regions was largely unknown to the central government. Swart [1970] reports that farming out taxes was a firmly established practice, e.g., in France, Spain, Turkey and China. The sale of offices, however, also gave rise to mechanisms of repeated extortion as described in this paper. When the official's contract was to be renewed, the ruler (king, emperor...) could use the information from the earlier sale of office, thus reducing the tax collector's incentive to invest in an efficient infrastructure for tax collection. Even worse, the ruler could expropriate his former tax collector -- a strategy that was already known to Roman emperor Titus Flavius Vespasianus (9-79 A.D.). ${ }^{16}$ He sold the offices of procuratores (tax collectors) to the most greedy men only to sentence them to high fines later on [Sturminger 1982$, pp. $105 f] .^{17}$

\section{Expropriation of Multinational Corporations}

When it comes to foreign direct investment (FDI), the interaction between a multinational firm and the government of the host country resembles in its structure the repeated extortion game analyzed in this paper. If the government cannot credibly commit to future tax rates (and certain property rights), this will make the foreign multinational more reluctant to invest in the country. Potential investors anticipate that their bargaining position versus the government is weakened once it has incurred the sunk costs of irreversible investments. The investors may mitigate the consequences of the unfavorable ex post bargaining position by reducing the capital intensity of their investment projects [Doyle and van Wijnbergen 1994]. As the lack of commitment to future tax rates works against the host country's own interests, it has an incentive to counteract the consequences of its own opportunistic ex post behavior by ex ante granting tax holidays. The potentially high tax payments in the future are compensated by a zero tax rate or even by subsidies in the initial period [Bond and Samuelson 1989].

\footnotetext{
${ }^{16}$ Vespasian was known for his rigor in tax collection to balance the government budget. He even introduced a tax on urine to be paid by tanners who used urine in the production process. When his son Titus felt disgusted and complained, Vespasian showed him a coin and responded with the now famous dictum: "Non olet" (Money doesn't stink).

${ }^{17}$ It is, however, not reported by historians whether this type of behavior was anticipated by the tax collectors and reduced their initial bids for the offices.
} 


\section{Appendix}

Appendix A1: Proof that it is optimal to have a constant number of firms in the market

\section{The Commitment Case}

Let us denote the marginal types in period 1 and period 2 as $v_{1}$ and $v_{2}$, respectively. We show that it is optimal for the official to have $v_{1}=v_{2}$.

Case 1. $v_{1}>v_{2}$

In this case, the official attracts new entrants in the second period. For this to happen, the second period demand should be $m_{2}=v_{2}-K$. For the marginal type $v_{1}$ to enter in the first period, the following two conditions must be satisfied:

$$
\begin{aligned}
& m_{1}+\delta \cdot m_{2} \leq v_{1} \cdot(1+\delta)-K \\
& \delta \cdot\left(v_{1}-\mathrm{K}-m_{2}\right) \leq v_{1} \cdot(1+\delta)-\mathrm{K}-\left(m_{1}+\delta \cdot m_{2}\right)
\end{aligned}
$$

The first one is that the marginal entrepreneur of type $v_{1}$ makes nonnegative profit with the first period entry. The second constraint is that he prefers to enter in the first period rather than to delay the entry until the second period. It can be easily verified that the first constraint is not binding. As a result, $m_{1}=v_{1}-(1-\delta) \cdot K$. We can write the revenue for the official as a function of the marginal types in each period:

$$
\text { (A.1) } R\left(v_{1}>v_{2}\right)=\left[v_{1}-(1-\delta) \cdot K\right] \cdot F\left(v_{1}\right)+\delta \cdot\left(v_{2}-K\right) \cdot F\left(v_{2}\right)
$$

which can be rewritten as:

$$
R\left(v_{1}>v_{2}\right)=\left[v_{1}-\frac{K}{1+\delta}\right] \cdot F\left(v_{1}\right)+\delta \cdot\left[v_{2}-\frac{K}{1+\delta}\right] \cdot F\left(v_{2}\right)+\left[F\left(v_{1}\right)-F\left(v_{2}\right)\right] \cdot \frac{\delta^{2} \cdot K}{1+\delta}
$$

Note that $\left[F\left(v_{1}\right)-F\left(v_{2}\right)\right]$ is a negative number when $v_{1}>v_{2}$.

Case 2. $v_{1}<v_{2}$

In this case, there is no new entry in the second period and some firms that entered in the first period exit in the second period. For this to happen, the corrupt official has to charge $m_{1}=v_{1}-K$ and $m_{2}=v_{2}$. Also for case 2, we calculate the official's revenue:

$$
\begin{aligned}
R\left(v_{1}<v_{2}\right) & =\left(v_{1}-K\right) \cdot F\left(v_{1}\right)+\delta \cdot v_{2} \cdot F\left(v_{2}\right)= \\
& =\left[v_{1}-\frac{K}{1+\delta}\right] \cdot F\left(v_{1}\right)+\delta \cdot\left[v_{2}-\frac{K}{1+\delta}\right] \cdot F\left(v_{2}\right)+\left[F\left(v_{2}\right)-F\left(v_{1}\right)\right] \cdot \frac{\delta \cdot K}{1+\delta}
\end{aligned}
$$

Note that $\left[F\left(v_{2}\right)-F\left(v_{1}\right)\right]$ is a negative number when $v_{1}<v_{2}$.

Case 3. $v_{1}=v_{2}$

In this case, the same firms are in the business in both periods. The marginal type is given by $v_{1}=v_{2}=v=\left(K+m_{1}+\delta \cdot m_{2}\right) /(1+\delta)$. The revenue for the official is:

$$
\begin{aligned}
R\left(v_{1}=v_{2}=v\right) & =[\mathrm{v} \cdot(1+\delta)-\mathrm{K}] \cdot F(v)= \\
& =\left[v_{1}-\frac{K}{1+\delta}\right] \cdot F\left(v_{1}\right)+\delta \cdot\left[v_{2}-\frac{K}{1+\delta}\right] \cdot F\left(v_{2}\right)
\end{aligned}
$$


The comparison of (A.1'), (A.2) and (A.3) makes it clear that the revenue for the official is maximized with monetary demands that induce $v_{1}=v_{2}$.

\section{The Non-Commitment Case}

To the contrary, assume that the optimal demand scheme induces $v_{1}>v_{2}$. Then, the second period marginal type is given as $v_{2}{ }^{*}=\operatorname{argmax}\left(v_{2}-K\right) \cdot F\left(v_{2}\right)$. The overall revenue for the official amounts to

$$
\begin{aligned}
R^{N C}\left(v_{1}>v_{2}\right) & =\left[v_{1}-(1-\delta) \cdot K\right] \cdot F\left(v_{1}\right)+\delta \cdot\left(v_{2}^{*}-K\right) \cdot F\left(v_{2}{ }^{*}\right) \\
& =\left(v_{1}-K\right) \cdot F\left(v_{1}\right)+\delta \cdot\left(v_{2}{ }^{*}-K\right) \cdot F\left(v_{2}{ }^{*}\right)+\delta \cdot K \cdot F\left(v_{1}\right)
\end{aligned}
$$

Thus, reducing $v_{1}$ closer to $v_{2}=v_{2}^{*}$ can increase the official's revenue by increasing both $\left(v_{1}-K\right) \cdot F\left(v_{1}\right)$ and $\delta \cdot K \cdot F\left(v_{1}\right)$. Thus, $v_{1}>v_{2}$ cannot be part of the optimal demand scheme.

Similarly, assume that the optimal demand scheme induces $v_{1}<v_{2}$. Then, the second period marginal entrepreneur is determined as $v_{2}^{* *}=\operatorname{argmax} v_{2} \cdot F\left(v_{2}\right)$. The overall revenue for the official is given by:

$$
\begin{aligned}
R^{N C}\left(v_{1}<v_{2}\right) & =\left[v_{1}-K\right] \cdot F\left(v_{1}\right)+\delta \cdot v_{2}^{* *} \cdot F\left(v_{2}^{* *}\right) \\
& =v_{1} \cdot F\left(v_{1}\right)+\delta \cdot v_{2}^{* *} \cdot F\left(v_{2}^{* *}\right)-K \cdot F\left(v_{1}\right)
\end{aligned}
$$

Thus, increasing $v_{1}$ closer to $v_{2}=v_{2}^{* *}$ can increase the official's revenue by increasing $v_{1} \cdot F\left(v_{1}\right)$ and decreasing $K \cdot F\left(v_{1}\right)$. Thus, $v_{1}<v_{2}$ cannot be part of the optimal demand scheme, either. QED.

\section{Appendix A2: Sketch of the proof for Proposition 3}

Suppose to the contrary that there is a pure strategy equilibrium where the official demands $m_{1}$ and $m_{2}$ in the first and second periods, respectively. Then, in this equilibrium, any type v such that

$$
\left(v-K-m_{1}\right)+\delta \cdot\left(v-m_{2}\right) \geq \max \left[v-k-m_{1}, 0\right]
$$

will enter with the $K$-technology. In other words, the choice of technology in the first period is characterized by a cut-off rule such that any type above the critical value $\hat{v}$ enters with the $\mathrm{K}$-technology, where $\hat{v}$ is defined by

$$
\left(\hat{v}-K-m_{1}\right)+\delta \cdot\left(\hat{v}-m_{2}\right)=\max \left[\hat{v}-k-m_{1}, 0\right] .
$$

That is,

$$
\hat{v}=\max \left[m_{2}+(K-k) / \delta, K+m_{1}+\delta m_{2} / 1+\delta\right]
$$

For $m_{2}$ to be the optimal choice for the official in the second period, $m_{2}$ should be either $\hat{v}$ or $m^{*}(k)$.

Suppose that $m_{2}=\hat{v}$. In this case, the critical type $\hat{v}$ who is supposed to choose the $K$-technology gets no surplus in the second period. As a result, the type $\hat{v}$ can be better off by deviating with the $\mathrm{k}$-technology and saving $(\mathrm{K}-\mathrm{k})$. Thus, we have a contradiction.

Suppose now that $m_{2}=m^{*}(k)$. For $m^{*}(k)$ to be the optimal choice in the second period, the marginal entrant $v=k+m^{*}(k)$ in the second period should have not entered with 
the $K$-technology in the first period. However, it can be easily verified that this type is better off with choosing the $K$-technology in the first period. Once again, we have a contradiction. QED.

\section{Appendix A3: Proof of Lemma 3}

In general, we allow that the second period demand by the official, $\widetilde{m}_{2}$, can be a random variable to accommodate the possibility of a mixed strategy. Then, given $m_{1}$, the expected value of entering with $K$-technology for type $v$ is given by:

$$
\pi(K, v)=v-K-m_{1}+\delta \cdot \mathrm{E}\left[\mathrm{v}-\widetilde{\mathrm{m}}_{2} \mid v \geq \widetilde{m}_{2}\right]
$$

Similarly, the expected value of entering with the $k$-technology is:

$$
\pi(k, v)=v-k-m_{1}+\delta \cdot \mathrm{E}\left[\mathrm{v}-\mathrm{k}-\widetilde{\mathrm{m}}_{2} \mid v \geq k+\widetilde{m}_{2}\right]
$$

The difference between these two choices is:

$$
\begin{aligned}
& \pi(K, v)-\pi(k, v)= \\
& =-(K-k)+\delta \cdot\left\{\mathrm{E}\left[\mathrm{v}-\widetilde{\mathrm{m}}_{2} \mid v \geq \widetilde{m}_{2}\right]-\mathrm{E}\left[\mathrm{v}-\mathrm{k}-\widetilde{\mathrm{m}}_{2} \mid v \geq k+\widetilde{m}_{2}\right]\right\}= \\
& =-(K-k)+\delta \cdot\left\{\mathrm{E}\left[\mathrm{v} \mid v \geq \widetilde{m}_{2}\right]-\mathrm{E}\left[\mathrm{v}-\mathrm{k} \mid v \geq k+\widetilde{m}_{2}\right]-\mathrm{E}\left[\widetilde{\mathrm{m}}_{2} \mid v \geq \widetilde{m}_{2} \geq v-k\right]\right\}
\end{aligned}
$$

Let $G($.$) denote the distribution of \widetilde{m}_{2}$, that is, $G(x)=\operatorname{Pr}\left[\widetilde{m}_{2} \leq x\right]$. Then,

$$
\begin{aligned}
\pi(K, v)-\pi(k, v) & =-(K-k)+\delta \cdot\left\{v \cdot G(v)-(v-k) \cdot G(v-k)-\int_{-k} \widetilde{m}_{2} d G\right\}= \\
& =-(K-k)+\int_{-k}^{v} G d \widetilde{m}_{2}
\end{aligned}
$$

where the last line follows by integration by parts.

As a result, we have

$$
\frac{\partial[\pi(K, v)-\pi(k, v)]}{\partial v}=G(v)-G(v-k) \geq 0
$$

Since $\pi(K, v)-\pi(k, v)$ is an increasing function of $v$, the choice of technology is characterized by a cut-off rule. 


\section{References}

Ades, Alberto and Rafael Di Tella, "The New Economics of Corruption: a Survey and some New Results," P. Heaywood, ed., Political Corruption (Oxford: Blackwell 1975), 80-99.

Bliss, Christopher and Rafael Di Tella, "Does Competition Kill Comuption?," Journal of Political Economy, 105 (1997), 1001-1023.

Bond, Eric W. and Larry Samuelson, "Bargaining with Commitment, Choice of Techniques, and Direct Foreign Investment," Journal of International Economics, 26 (1989), 77-97.

Cournot, Augustine, Researches into the Mathematical Principles of the Theory of Welath, original published in French (1838), translated by Nathaniel Bacon (New York: Macmillan 1927)

Doyle, Chris and Sweder van Wijnbergen, "Taxation of Foreign Multinationals: A Sequential Bargaining Approach to Tax Holidays," International Tax and Public Finance, 1 (1994), 211-225.

Farrell, Joseph and Nancy T. Gallini, "Second-Sourcing as a Commitment: Monopoly Incentives to Attract Competition," Quarterly Journal of Economics, 103 (1987), 673694.

Fesler, James W. and Donald F. Kettl, The Politics of Administrative Process (Chatham, NJ: Chatham House, 1991).

Freixas, Xavier, Roger Guesnerie, and Jean Tirole, "Planning under Incomplete Information and the Ratchet Effect," Review of Economic Studies, 52 (1985), 173-192.

Fudenberg, Drew and Jean Tirole, Game Theory (Cambridge, MA: MIT Press, 1991).

Giuliani, Rudolph W., Freeing the Economy from Organized Crime and Restoring Open, Competitive Markets, 23 October 1997, Office of the Mayor, New York City.

Gould, David J., Bureaucratic Corruption and Underdevelopment in the Third World: The Case of Zaire (New York: Pergamon, 1980).

Huntington, Samuel P., Political Order in Changing Societies (New Haven, CT: Yale University Press, 1968).

Ickes, Barry W. and Larry Samuelson, "Job Transfers and Incentives in Complex Organizations: Thwarting the Ratchet Effect," Rand Journal of Economics, 18 (1987), 275-286.

IMF, IMF Adopts Guidelines Regarding Governance Issues, News Brief No. 97/15, August 4, 1997, Washington, DC: International Monetary Fund.

Klitgaard, Robert, Tropical Gangsters (New York: Basic Books, 1990).

Konrad, Kai A. and Stergios Skaperdas, "Backing up Words with Deeds: Information and Punishment in Organized Crime," Nordic Journal of Political Economy, 24 (1997), 51 63.

Konrad, Kai A. and Stergios Skaperdas, "Extortion," Economica, forthcoming.

Laffont, Jean-Jacques and Jean Tirole, “The Dynamics of Incentive Contracts," Econometrica, 56 (1988), 1153-1175.

Leff, Nathaniel H., "Economic Development through Bureaucratic Corruption," American Behavioral Scientist, 8 (1964), 8-14. 
Mauro, Paolo, "Corruption and Growth," Quarterly Journal of Economics, 110 (1995), 681712.

Miller, Barry R., "Confiscation, Credible Commitment and Progressive Reform in the United States," Journal of Institutional and Theoretical Economics, 145 (1989), 686-692.

Noonan, John T., Bribes (New York: Macmillan, 1984).

North, Douglass C. and Barry R. Weingast, "Constitutions and Commitment: The Evolution of Institutions Governing Public Choice in Seventeenth-Century England," Journal of Economic History, 49 (1989), 803-832.

Rose-Ackerman, Susan, "The Economics of Corruption," Journal of Public Economics, 4 (1975), 187-203.

Scott, James C., Comparative Political Corruption (Englewood Cliffs, NJ: Prentice-Hall, 1972).

Shleifer, Andrei and Robert W.Vishny, "Corruption," Quarterly Journal of Economics, 108 (1993), 599-617.

Stigler, George J., "The Theory of Economic Regulation," Bell Journal of Economics and Management Science, 2 (1971), 1-21.

Sturminger, Alfred, Die Korruption in der Weltgeschichte (Corruption in World History) (Munich: Langen Müller, 1982).

Swart, Koenraad W., "The Sale of Public Offices," A.J. Heidenheimer, ed., Political Corruption - Readings in Comparative Analysis (New York: Holt, Rinehart \& Winston, 1970), 82-90.

Telser, Lester G., "A Theory of Monopoly of Complementary Goods," Journal of Business, 52 (1979), 211-230.

Viscusi, W. Kip, John M. Vernon, and Joseph E. Harrington, Jr., Economics of Regulation and Antitrust (Cambridge, MA: MIT Press, 1995)

Vuliamy, Ed, "Mafia on Trial", The Observer, 19 April 1998.

Wei, Shang-Jin, How Taxing is Corruption on International Investors?, NBER Working Paper No. 6030, May 1997a.

Wei, Shang-Jin, Why is Corruption So Much More Taxing Than Tax? Arbitrariness Kills, NBER Working Paper No. 6255, November 1997b.

World Bank, World Development Report 1997: The State in a Changing World, (Oxford: Oxford University Press, 1997) 


\title{
1998-1999 Discussion Paper Series
}

\author{
Department of Economics \\ Columbia University \\ 1022 International Affairs Bldg. \\ 420 West 118th Street \\ New York, N.Y., 10027
}

The following papers are published in the 1998-99 Columbia University Discussion Paper series which runs from early November to October 31 of the following year (Academic Year).

The following is the Columbia University, Economics Department's website where viewers may access more information about the Discussion Paper series.

\section{Http://www.columbia.edu/cu/economics/}

All 1997-98, 1998-99 and future papers will be acessible on-line at the following website:

\section{Http://www.ssrn.com}

Discussions papers that are not available on-line maybe obtained by written request to the Economics Department. Please check the Ordering Papers section for details.

\section{Copy Requests}

To order 1996-97 and prior discussion papers, please write to the Discussion Paper Coordinator at the address below, along with a check for the appropriate amount, made payable to:

Department of Economics, Columbia University. Please be sure to indicate the discussion paper number or the particular series in your written request. Orders cannot be processed without payment, and they cannot be taken over the phone, or by fax or email.

Past discussion papers (1996-97 and prior papers) are available for purchase in U.S. dollars only, at the cost of:

US: per paper $\$ 4.00 /$ per series: $\$ 140.00$

Canada: per paper $\$ 5.00 /$ per series: $\$ 150.00$

Overseas: per paper $\$ 7.00 /$ per series $\$ 185.00$ 
1998-99 Discussion Papers

Economics Department, Columbia University

\begin{tabular}{|c|c|c|}
\hline 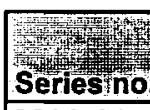 & 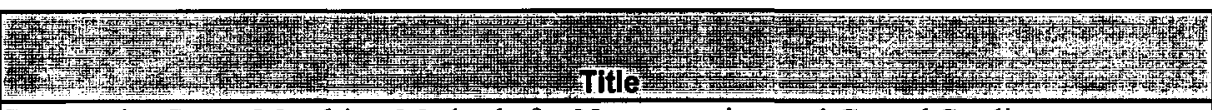 & Thuthors \\
\hline $9899-01$ & Propensity Score Matching Methods for Non-experimental Causal Studies & Dehejia, R. \\
\hline $9899-02$ & Institutional Solutions to the Principal-Agent Problem in African Health Care & $\begin{array}{l}\text { Leonard, } \mathrm{K} . \\
\text { Leonard, D. }\end{array}$ \\
\hline $9899-03$ & The Economics of Repeated Extortion & $\begin{array}{l}\text { Choi, J.P. } \\
\text { Thum, M. }\end{array}$ \\
\hline
\end{tabular}

